\title{
A QUESTÃO DA VERDADE NA POLÍTICA
}

\section{THE QUESTION OF TRUTH IN POLITICS}

Daiane Soares dos Santos*

José João Neves Barbosa Vicente**

\section{RESUMO}

A proposta deste artigo é refletir em torno da questão da verdade no âmbito da política, a partir dos estudos desenvolvidos por Arendt em sua obra Entre o passado $e$ o futuro, especificamente no capitulo intitulado "Verdade e política".

PALAVRAS CHAVE: Política. Mentira. Verdade

\begin{abstract}
The purpose of this article is to reflect around the question of truth in the context of politics, from the studies developed by Arendt in his work Between the past and the future, specifically in the chapter titled "truth and politics".
\end{abstract}

KEYWORDS: Politics. Lie. Truth.

\section{Introdução}

Em meio a tantos escândalos públicos a cerca da desonestidade na condução da vida política, como por exemplo, nepotismo, improbidade administrativa, desvios de verbas e mau uso de recursos públicos, é perceptível a indignação da população perante tantos escândalos de corrupção, sem que os acusados sejam devidamente investigados e punidos. Nas rodas de conversas, nas filas, no trabalho, nas redes sociais, enfim, no dia a dia da vida cotidiana cometam-se as falcatruas estampadas nos jornais e revistas de circulação nacional, nos noticiários de telejornais, nos blogs e meios de comunicação midiática em geral. A população

\footnotetext{
* Licenciada em Filosofia pela Universidade Federal do Recôncavo da Bahia (UFRB). E-mail: daisoares.s@gmail.com

** Mestre em Filosofia pela Universidade Federal de Goiás (UFG), doutorando em Filosofia na Universidade Federal da Bahia (UFBA) e professor de Filosofia da Universidade Federal do Recôncavo da Bahia (UFRB)
} 
diz-se indignada com tanta denúncia de corrupção e descrente da honestidade no meio político. Frente a essa situação, a política é vista, pelo senso comum, como sinônimo de desfalque, desvio, negociata, dissimulação. Igualmente acredita-se que a verdade não faz parte do meio político, antes o que prevalece é a desonestidade, o logro, a trapaça, a fraude e todo tipo de tentativa de enganar, iludir, mentir.

Tendo em vista o dito descontentamento dos cidadãos, propomos os seguintes questionamentos: seria a verdade o objetivo a se ter em vista no meio público? A realidade é pretendida ao invés da ilusão? Qual o lugar da verdade na política? Verdade e política estabelecem uma relação de incompatibilidade? Qual a relação estabelecida entre verdade e Política?

Dito isto, nossa investigação diz respeito, justamente ao lugar da verdade na política, tendo como guia o pensamento de Arendt, como aparece, principalmente em sua obra Entre $o$ passado e o futuro. Se tratando do âmbito político, que é nosso campo de pesquisa, procuramos investigar onde se insere o contexto da Política, se a verdade é o seu campo de atuação e se na forma de condução da vida pública prevalece a mentira ou a verdade. Ousamos dizer que a filosofia tem por objeto a verdade, que o filosofar surge no momento em que decidimos procurar o ser verdadeiro de cada coisa.

Arendt possui como principal característica o cuidado no tratamento dos conceitos, e assim sendo procuramos apresentar no decorrer do nosso processo investigativo a delimitação feita por ela dos principais conceitos analisados em Entre o passado e o futuro, quais sejam, autoridade, história e liberdade. No tocante a verdade, ela distingue a verdade racional que diz respeito às investigações filosóficas, matemáticas e cientificas, da verdade factual que referese a acontecimentos, eventos e fatos que por sua vez estão a mercê de serem interpretados.

Em nossa investigação acerca da questão da verdade no âmbito político, percebemos que o que parece estar no cerne da questão não é a busca por algo que sustente a possibilidade de alcançarmos um conhecimento dito universal, mas sim um tipo de parâmetro que assegure que nossas ações são guiadas por meios corretos e não prejudiciais, mais que isso, uma espécie de "autoridade" por assim dizer que dará a última palavra no tocante as ações humanas, uma espécie de guia que determine a melhor condução da vida em comum.

Tema caro a filosofia, a questão da verdade, nos levou a remontar a origem do filosofar na Grécia antiga onde essa aparece como idêntica ao que é real e em oposição à aparência, à ilusão e à opinião. Num sentido platônico, podemos dizer que ela é tida como um fim a que tudo e todos devem ter em vista, uma vez que ela traduz a realidade que se encontra 
no mundo das ideais, no âmbito do puramente racional em que aquele que for capaz de elevar sua alma para a busca do bem em si, poderá desvelar a verdade e bem conduzir a polis. Veremos adiante que este será o filósofo. Assim sendo, pretendemos de início apresentar o lugar da verdade, tentando problematizar o seu valor enquanto princípio absoluto na concepção grega clássica, sobretudo em Platão. Em seguida, seguiremos a análise feita por Arendt, acerca do rompimento da época moderna com modelos tradicionais de pensamento e suas possíveis consequências no mundo contemporâneo, assim como sua leitura acerca do que fora o conceito de autoridade, a relação estabelecida entre Política e liberdade e, por fim, deslindar a relação entre verdade e política no pensamento de Arendt.

\section{Origem da política}

No primeiro capítulo de Entre o passado e o futuro, Arendt nos diz que a tradição do pensamento político tem inicio com Platão, em sua obra A república:

\footnotetext{
O início deu-se quando, na alegoria da caverna, em A República, Platão descreveu a esfera dos assuntos humanos, tudo aquilo que pertence ao convívio de homens em um mundo comum, em termos de trevas, confusão e ilusão, que aqueles que aspirassem ao ser verdadeiro deveriam repudiar e abandonar, caso quisessem descobrir o céu límpido das ideias eternas (ARENDT, 2014, p.43).
}

A cidade tem sua origem no fato de não sermos autossuficientes. Esta, assim como a alma de cada indivíduo é dividida em três elementos distintos: o racional, o concupiscível e o irascível. No âmbito político, que só pode ocorrer na polis, a justiça consiste na realização por parte de cada indivíduo da sua tarefa, e no não intrometimento nas tarefas alheias; desta forma deve-se ter em vista a unidade evitando a todo custo a multiplicidade. A justiça é justamente o princípio que deve guiar a fundação da cidade. E para que assim seja, é preciso que cada um ocupe-se, de acordo com sua natureza, da sua devida função. O homem, tal qual a cidade, será justo quando toda alma obedecer à parte filosófica podendo, assim, colher benefícios e pôr fim aos males. Nesse contexto, a realidade está associada àquilo que é imutável e imortal, portanto o mutável e mortal estão vinculados ao o mundo da aparência, e assim sendo, não passam de ilusões. A justiça, portanto, consiste, exatamente, na adequada execução da tarefa de cada cidadão. O contrário disto consiste no maior dano para com a cidade que é a injustiça.

Para que tudo funcione em harmonia, é preciso que o "filósofo" se tornar o governante da cidade, pois enquanto não houver a junção entre filosofia e política, enquanto não houver a 
devida distinção das naturezas e estas não ocuparem seus devidos lugares, a cidade não será guiada adequadamente e não haverá interrupção dos danos. E quem é o filósofo e por que cabe a ele a função de governar a cidade? O filósofo é o amante da verdade e busca a realidade, é "aquele que [...] entende que existe o belo em si e é capaz de contemplar, na sua essência e nas coisas em que tem participação, e sabe que as coisas não se identificam com ele, nem ele com as coisas" (PLATÃO, A república, 476b). O filósofo é capaz de enxergar os objetos iluminados pela verdade e pode, também, transmitir a verdade.

\section{A história e o rompimento com a tradição}

A partir da reflexão sobre os acontecimentos políticos do século XX, na tentativa de entender a profunda crise que assolava a época contemporânea, Arendt se debruça sobre a lacuna entre o passado o futuro já iniciada no período moderno. Como é sabido, com o advento da idade moderna ocorreram diversas mudanças no tocante a aspectos materiais, religiosos, econômicos, sociais, científicos e políticos. Kierkegaard, Marx e Nietzsche, mais precisamente no século XIX, situados no fim da tradição, inauguraram uma nova maneira de pensar a Filosofia representando o rompimento com a tradição no tocante a religião, ao pensamento político e a Metafísica.

Kierkegaard pretende afirmar o caráter concreto do indivíduo enquanto sofredor em oposição à clássica definição do homem enquanto racionalidade. A fé que requer o mais alto grau de subjetividade é a verdade por excelência. Em relação à verdade, para Kierkegaard, ela está para ser vivida e não pensada, isso porque a verdade é compreendida enquanto singularidade, a realidade existencial e indizível de cada indivíduo. E sendo assim, a verdade não pode ser uma imposição exterior ao indivíduo. (JOLIVET, 1961, p.47-49) Isso fica claro, por exemplo, quando o pensador dinamarquês se posiciona de forma crítica perante a filosofia do Sistema desenvolvida por Hegel, que pretende explicar a existência, reduzindo-a a puros conceitos racionais, retirando o caráter concreto da existência humana, o que significa dizer que não há uma existência verdadeira. A conceituação racional não abrange o devir, a individualidade, a contradição paradoxal no aqui e no agora da realidade existencial.

Nietzsche adota uma postura crítica frente a qualquer tentativa de dizer a verdade. Para ele, o mundo não é constituído por coisas dadas a espera de serem desveladas pela razão humana. O mundo não está para ser explicado, mas interpretado, não está para ser descoberto, mas inventado. Ele coloca as coisas a partir de múltiplas perspectivas e não apenas por meio 
de uma única interpretação que defina como as coisas são, pretende afirmar a vida como vontade de potência, vontade de criar, expandir, crescer, gerar. O que precisa ser afirmado é a vida do momento presente, a vida que ao mesmo tempo em que faz do pensamento algo de ativo deve ser afirmada por ele. (DIAS, 2011, p.58). Para Arendt (ARENDT, 2014, p.57), o salto de Nietzsche é do mundo das ideias, transcendente e suprassensível para a vida do sensualismo, uma espécie de platonismo invertido.

De acordo com a filósofa, o salto de Marx por sua vez é da teoria para a ação, da contemplação para o trabalho, da Filosofia para a Política. Ela faz uma análise dos principais pressupostos marxista mostrando o quanto são desafiadores e paradoxais, por exemplo, o trabalho criou o homem, a violência é a parteira da história e a realização da Filosofia na Política. Alerta, ainda que a compreensão dessas proposições só pode ser feita a partir da refutação de verdades tradicionais e até então indubitáveis. A ideia de que o trabalho criou o homem significa que o homem nem é criatura de Deus e nem é um animal racional, mas antes é criador de si mesmo, resultado da sua própria atividade é um animal laborans e sua humanidade reside no trabalho. Aqui já fica evidente a incompatibilidade com o pensamento clássico no tocante a Deus, enquanto criador do homem, a razão enquanto seu atributo máximo e a valorização do trabalho até então menosprezado. A violência enquanto parteira da História significa que o campo da ação política é o campo da violência. Essa ideia vai de encontro a ideia clássica, sobretudo de Aristóteles, da condução dos assuntos políticos através do diálogo entre homens livres, da persuasão por meio da palavra que distinguia os gregos dos bárbaros e escravos. No tocante a realização da Filosofia na Política, implica que o filósofo deve interpretar o mundo para conduzi-lo rumo à transformação, ou seja, o mundo deve ser transformado de acordo com a Filosofia. Essa proposta desafia a tradição no tocante a confluência entre senso comum e Filosofia (ARENDT, 2014, p.47-48).

É Marx, portanto, que defende que um dia a Filosofia tornar-se-á uma realidade para todos, diferentemente do pensamento platônico em que a filosofia estava reservada para eleitos. Esses desafios à tradição, de acordo com Arendt, não representam a ruptura com a História Ocidental que só veio acontecer no século XX, com o acontecimento inédito do totalitarismo.

Precedidos por Hegel, os três pensadores apresentados no fim da tradição, antes da ruptura, não podem ser considerados culpados pelos desdobramentos do mundo contemporâneo marcado por grandes guerras e revoluções. Antes, representam a fronteira da perda da autoridade do passado, são pensadores que abriram mão da autoridade de qualquer 
pensamento anterior. Todavia, isso não significa que conceitos tradicionais tenham perdido seu poder, até porque faziam uso desses mesmos conceitos para efetuarem suas críticas, fizeram a inversão hierárquica desses conceitos a partir do próprio referencial teórico da tradição. Nas palavras de Arendt:

\begin{abstract}
O conceito central da metafísica hegeliana é a História. Isto basta para colocá-la na oposição a mais aguda possível frente toda a Metafísica anterior que desde Platão buscara a verdade e a revelação do Ser eterno em toda parte, exceto na esfera dos problemas humanos, de que Platão fala com tamanho desprezo precisamente porque nela não se poderia achar nenhuma permanência, não se podendo pois esperar que desvelasse a verdade. Pensar, com Hegel, que a verdade reside e se revela no próprio processo temporal é característico de toda a consciência histórica moderna, como quer que esta se expressa em termos especificamente hegelianos ou não (ARENDT, 2014, p.101).
\end{abstract}

Para Hegel a totalidade da história Universal segue um desenvolvimento contínuo, essa visão de continuidade histórica substitui e recusa a autoridade de todas as tradições. Para os gregos com o fito de garantir a imortalidade do homem na terra, a História registrava fatos e acontecimentos grandiosos, isso porque a natureza era imortal e o homem enquanto mortal poderia se imortalizar por meio do registro de feitos heroicos. A concepção moderna, que reside em Vico, distingue processos naturais de processos históricos. Assim, só Deus criador da natureza pode entender seus processos, e sendo a História feita por Homens, logo este é capaz de compreender seus processos, uma vez que ele mesmo os desencadeou. Tanto para Vico, quanto para Hegel, o historiador e o filósofo por serem capazes de abarcar a totalidade do processo histórico são capazes de revelar a verdade a partir do seu olhar contemplativo. Isso porque a História é posterior aos acontecimentos cabendo ao historiador que vê o processo como um todo o compreendê-lo adequadamente. Para estes o conceito de História tinha sua importância apenas teórica, não pretendiam utilizar esse conceito como um princípio de ação como fez Marx, por exemplo (ARENDT, 2014, p.112).

\title{
Autoridade e liberdade
}

Que tipo de tradição existia anterior aos rompimentos do mundo moderno com todo tipo de autoridade? É essa questão que Arendt pretende refletir no terceiro capítulo de Entre $O$ passado e o futuro, intitulado Que é Autoridade? Ela toma muito cuidado com o tratamento dos conceitos, fazendo a devida delimitação dos termos utilizados. Ela reconhece que, por esta ter desaparecido do mundo moderno, não é cabível responder a pergunta o que é 
autoridade, assim, ela propõe uma reconsideração do que foi historicamente a autoridade recorrendo a seus referencias de significação e valorização. Termo outrora fundamental na teoria política, a autoridade encontra-se no mundo moderno em meio ao descrédito e confusão e, frequentemente, é "confundida como alguma forma de poder ou violência", mas a verdade é que ela "exclui a utilização de meio externos de coerção; onde a força é usada, a autoridade em si mesmo fracassou". A autoridade, portanto, é, em essência, "incompatível com a persuasão, a qual pressupõe igualdade e opera mediante um processo de argumentação" (ARENDT, 2014, P.129).

O conflito entre os teóricos liberais e conservadores na tentativa de reafirmar hora a liberdade, hora a autoridade, acabaram por confundir ainda mais os conceitos, destruindo seus respectivos significados políticos. Num contexto de desinteresse da distinção dos termos, a preocupação estava voltada somente para as funções que esses exerciam, nesse sentido tratavam conceitos distintos como sendo a mesma coisa. Por estes exercerem uma mesma função, logo "se a violência preenche a mesma função que a autoridade, a saber, faz com que as pessoas obedeçam, então violência é autoridade" (ARENDT, 2014, p.140). Dessa forma, tudo aquilo que tiver por função fazer com que as pessoas obedeçam, será denominado de autoridade, aqui Arendt tece sua crítica a esta forma de tratamento dos termos apontando os erros incorridos de tomar uma coisa por outra.

Assim como ocorre com o conceito de autoridade, a liberdade também recebe a atenção de Arendt que acredita que no que tange a política, o problema da liberdade é extremamente importante e igualmente encontra-se envolta a escuridão. A causa da confusão em torno da ideia da liberdade, é a identificação do surgimento da liberdade no âmbito do pensamento, isso porque a Filosofia, se deu conta da liberdade somente no relacionamento interior do indivíduo consigo mesmo. A tradição filosófica não clarificou esse conceito, ao contrário confundiu as coisas ao transferir a liberdade do campo da Política, para o campo da interioridade, isto é, o campo da vontade. O campo original da liberdade é o da ação humana, o âmbito da política e, por sinal, não é possível conceber a ação e a política sem pressupor a existência da liberdade, o que implica na dificuldade de tratar de qualquer assunto político sem tocar direta ou indiretamente em um problema da liberdade. Em síntese, a liberdade é o motivo da existência da política, o que possibilita o convívio do homem em comunidade organizada, o que significa que sem a liberdade a vida política perde seu sentido (ARENDT, 2014, p.191-192). 
Esse parece ser o dilema que Arendt encontra ao tratar do problema da liberdade, que este é aceito pela Filosofia no domínio apolítico, enquanto que na verdade o homem só pode se dar conta da liberdade ou da falta dela convivendo com outros homens em um mundo comum, pois a liberdade só aparece no que concerne ao domínio público da política. Dito de outra forma, a tradição filosófica lida com o problema da liberdade no relacionamento do eu consigo mesmo, fora do domínio público em que é estabelecida a relação com outras pessoas, o que quer dizer que a liberdade começa num campo contrário ao da vida política. (ARENDT, 2014, p.194). Arendt nos diz que a liberdade e a política estabelecem uma relação intrínseca; liberdade atrelada a política, definitivamente não é um elemento da vontade. A dificuldade em aceitar essa relação entre liberdade e política reside no fato das teorias em geral identificarem a liberdade como elemento da vontade e do pensamento, ao invés de identificá-la como um princípio da ação. E isso tem suas implicações no fato da liberdade só se tornar interesse da Filosofia enquanto livre-arbítrio, enquanto princípio do querer e da relação do eu consigo mesmo. (ARENDT, 2014, p.197).

Outra observação importante feita por Arendt, diz respeito a distinção entre liberdade e livre-arbítrio. A liberdade que tem a ver com o âmbito da político, não é a possibilidade de escolher entre isto ou aquilo, que diz respeito ao indivíduo no seu relacionamento interior e indiferente as demais pessoas, mas a liberdade de trazer algo novo a existência, um princípio político que é vivenciado na ação e no relacionamento com outros e não consigo mesmo (ARENDT, 2014, p.198). Com o não reconhecimento da importância da devida distinção dos assuntos sociais, históricos e políticos, Arendt aponta a confusão feita pelos teóricos tanto conservadores, quanto liberais no tocante aos conceitos de autoridade.

\section{Verdade e política}

A linha entre a verdade e a política é tênue, no sentido que a relação estabelecida entre ambas é vista como sendo de incompatibilidade, por assim dizer. É como se a verdade não sobrevivesse no âmbito político, ou antes, como se a mentira é que tivesse lugar privilegiado nas relações políticas. O descrédito da verdade é visível na constante suspeita da falta de sinceridade no tocante a condução das organizações públicas. Colocar em questão o valor da verdade em detrimento da interrupção da existência do mundo é uma forma de colocar a mentira como sendo justificável e necessária. Não tem sentido falar em continuidade da existência sem o testemunho das coisas como elas são enquanto são. 
No período moderno em que a verdade aparece como uma produção da mente humana há a distinção entre verdade racional e verdade fatual. Arendt não coloca em jogo a legitimidade dessa distinção, não tem pretensões filosóficas de refletir sobre o que a verdade é, antes faz uso da palavra em seu sentido usual com objetivos unicamente políticos de investigar quais os prejuízos provenientes do poder para com a verdade.

Um primeiro ponto observado é que a verdade de fato é mais vulnerável do que a verdade racional, ou seja, as proposições matemáticas, cientificas e filosóficas são menos prováveis ao desaparecimento total, tal como está sujeita as questões fatuais. A verdade racional está para além dos limites da política, enquanto que a verdade de fato encontra-se dento de seus domínios, pois fatos e eventos constituem o resultado das ações humanas em conjunto. Assim sendo, ao negar os fatos, fazendo uso de mentiras, as chances de seu desaparecimento é eminente, correndo maior risco de serem extintas pelo poder político do que as verdades racionais.

Já na Grécia Antiga percebe-se o conflito existente entre a tentativa da junção entre a verdade filosófica e os assuntos da vida pública. Falar dessa relação é uma questão bastante delicada, desde a origem da política com Platão temos relatos dos conflitos existentes entre aqueles que dizem a verdade e os demais cidadãos. Dizer a verdade implicava correr riscos, riscos estes que se originavam da tentativa de salvaguardar seus conterrâneos, desprovidos da contemplação do ser verdadeiro das coisas, da falsidade e da ilusão. É como se a verdade não atraísse a multidão, que antes pareciam preferir as trevas da ilusão.

Há uma verdade que seja universal, no sentido que abrange a todos e não apenas a poucos eleitos? No período moderno Hobbes, por exemplo, fala de uma verdade bem vista por todos, desde que esta não se oponha ao lucro e ao prazer humano. Platão, por sua vez não concordaria que possa existir algum tipo de verdade bem vista por todos em uníssono. Que espécie de verdade diz respeito e/ou mantém relação com a Política? São as verdades fatuais que estão em jogo no tocante ao âmbito da política, e não as verdades racionais, apesar do relacionamento entre verdade e política já aparecer sobre aspectos conflituosos nos polos opostos da vida do filósofo e do cidadão ateniense. (ARENDT, 2014, p.1286-288).

O contrário das verdades racionais versa entre opinião, erro, ilusão e ignorância. Dessa forma, a mentira é desconsiderada e só passa a fazer parte do debate no que tange as verdades fatuais. Arendt acha curioso o fato de a mentira organizada não ter sido considerada como uma arma eficaz contra a verdade. Afirma que o que distingue a verdade fatual é justamente a mentira enquanto seu polo oposto. 
Uma vez que assegura as coisas como elas são, dizer a verdade não denota ação assim como ocorre com a mentira, pois esta distorce os acontecimentos, destrói o sentido por meio do qual nos guiamos no mundo, aquilo que ela nega é destruído o que invoca certo aspecto de violência. Outro aspecto relevante apontado a cerca da mentira é que ela confirma a liberdade humana, devido justamente a seu poder de ação.

No contexto em que Arendt viveu e que foi imprescindível para suas reflexões, o conflito implicava em questões que iam além da tensão entre o filósofo e o mundo ordinário. O cerne do problema estava entre uma realidade igualmente compartilhada das questões de fato. É como se aquele que diz a verdade fatual se encontrasse em situação um pouco mais delicada, tendo em vista que a verdade quando contradita não é a de um mundo que está além e que só é contemplado em solidão, mas sim a verdade de acontecimentos do mundo comum em que todos podem vivenciar.

\footnotetext{
Contudo, o relator da verdade fatual está ainda mais deslocado. Ele não retorna de nenhuma jornada por regiões além do âmbito dos negócios humanos, e não se pode consolar com o pensamento de que se tornou um estrangeiro nesse mundo. Similarmente, não temos nenhum direito de nos consolarmos com a noção de que sua verdade, se verdade há de ser, não é desse mundo. Se suas simples afirmações fatuais não são aceitas - as verdades vistas e testemunhadas com os olhos do corpo, e não com os olhos da mente -, surge a suspeita de que pode estar na natureza do âmbito político negar ou perverter a verdade de toda espécie, como se os homens fossem incapazes de chegar a bom termo com sua tenaz, clamorosa e obstinada teimosia (ARENDT, 2014, p.294-295).
}

Diferentemente da verdade do filósofo que é uma contemplação solitária, a verdade fatual está relacionada com o convívio entre iguais, não diz respeito ao empreendimento racional do homem singular, mas sim ao compartilhamento de acontecimentos legitimados pelo testemunho de vários homens, é dialógica e necessita que se fale dela pra existir, o que significa que tem seu lugar de existir na política. Fatos e opiniões se apresentam no campo político, não são opostos e poderem sobreviver separadamente. Os acontecimentos fatuais informam o pensamento político e, portanto, a liberdade de opinião deve assegurar a informação fatual para que os fatos não sejam postos sob dúvida.

Um outro ponto que parece ser de suma importância nessa discussão é a relação entre fatos e opiniões. Filósofos que se ocuparam com a história e historiadores afirmam ser inconcebível demonstrar fatos sem interpretação, a estória tem origem da organização dos acontecimentos a partir de determinada perspectiva que difere de seu acontecimento original. Contudo, Arendt observa que não é aceitável ultrapassa esse limite da interpretação 
modificando o próprio conteúdo do fato. Afirma ainda, que se o interesse do poder determinasse as questões relativas as verdades fatuais poder-se-ía supor os rumos que as coisas tomariam, levando-a a suspeita de que pode ser próprio da política estar em desacordo com a verdade e que até mesmo em relação aos fatos, parece ser este incompatível com a política.

Arendt observa que todas as verdades, sejam racionais ou fatuais, são opostas a opinião no tocante a corroborar sua validade. Os fatos simplesmente acontecem, da mesma forma que poderiam não acontecer, dizem respeito ao passado e estão além de qualquer tipo de acordo ou consentimento. A guisa de conclusão, tentamos nessa última seção apontar alguns aspectos que julgamos principais da investigação de Arendt, ao que diz respeito a relação estabelecida entre a verdade e a política. Apesar da relação conflituosa que foi aqui evidenciada, a autora assegura a dignidade tanto da verdade quanto da política. A despeito de toda invertida do poder contra a verdade sua força prevalece, uma vez que não pode ser destruída pela persuasão e pela violência, muito menos ser substituída por estas. No tocante a política esta aparece como sendo um lugar que prevalece todo tipo de interesses parciais que visam o lucro e o desejo de poder. Isso porque, a verdade fatual assim como a verdade filosófica entra em choque com a política exatamente no domínio dos assuntos humanos. Contudo, resguarda a dignidade da política no convívio entre iguais, da ação em conjunto, enfim, do compartilhamento da vida pública. Assim sendo, seu objetivo foi mostrar que apesar da sua grandeza, a política possui limites tendo em vista a totalidade da existência humana a qual ela não consegue abarcar. (ARENDT, 2014, p.325).

\section{Conclusão}

Não é nenhuma surpresa hoje, concluir um texto que trata da verdade na política, afirmando que verdade e política não se dão bem uma com a outra. Afinal, é praticamente impossível encontrarmos na história do pensamento político, ou na história da prática política, a sinceridade como sendo a sua virtude principal. Pelo contrário, nas práticas políticas, a mentira e a desonestidade foram tomadas sempre como ferramentas fundamentais, enquanto a verdade ficou sempre esquecida. De um modo geral, portanto, foram e ainda são as mentiras e a desonestidade as principais armas do oficio do político, do demagogo e do estadista. 


\section{Referências}

ARENDT, Hannah. Entre o passado e o futuro. Trad. Mauro Barbosa. São Paulo: Perspectiva, 2014.

DIAS, Rosa. Nietzsche, vida como obra de arte. Rio de Janeiro: Civilização brasileira, 2011.

JOLIVET, Regis. As doutrinas existencialistas. Trad. António de Queirós Vasconcelos e Lencastre. Porto: Livraria Tavares Martins, 1961.

PLATÃO. A República. Trad. Maria Helena da Rocha Pereira. Lisboa: Calouste Gulbenkian, 1996. 